\title{
Using spectral indices to estimate water content and GPP in Sphagnum moss and other peatland vegetation
}

Article

Accepted Version

Lees, K. J., Artz, R. R. E., Khomik, M., Clark, J. M., Ritson, J., Hancock, M. H., Cowie, N. R. and Quaife, T. (2020) Using spectral indices to estimate water content and GPP in Sphagnum moss and other peatland vegetation. IEEE Transactions on Geoscience and Remote Sensing, 58 (7). pp. 4547-4557. ISSN 0196-2892 doi:

https://doi.org/10.1109/TGRS.2019.2961479 Available at https://centaur.reading.ac.uk/88076/

It is advisable to refer to the publisher's version if you intend to cite from the work. See Guidance on citing.

To link to this article DOI: http://dx.doi.org/10.1109/TGRS.2019.2961479

Publisher: IEEE Geoscience and Remote Sensing Society

All outputs in CentAUR are protected by Intellectual Property Rights law, including copyright law. Copyright and IPR is retained by the creators or other copyright holders. Terms and conditions for use of this material are defined in the End User Agreement. 


\section{CentAUR}

Central Archive at the University of Reading

Reading's research outputs online 


\title{
Using Spectral Indices to estimate Water Content and GPP in Sphagnum Moss and other Peatland Vegetation
}

\author{
Kirsten J. Lees, Rebekka R.E.Artz, Myroslava Khomik, Joanna M. Clark, Jonathan Ritson, Mark \\ H.Hancock, Neil R. Cowie, \& Tristan Quaife
}

\begin{abstract}
Peatlands provide important ecosystem services including carbon storage and biodiversity conservation. Remote sensing shows potential for monitoring peatlands, but most off-the-shelf data products are developed for unsaturated environments and it is unclear how well they can perform in peatland ecosystems. Sphagnum moss is an important peatland genus with specific characteristics which can affect spectral reflectance, and we hypothesized that the prevalence of Sphagnum in a peatland could affect the spectral signature of the area. This study combines results from both laboratory and field experiments to assess the relationship between spectral indices and the moisture content and GPP of peatland (blanket bog) vegetation species. The aim was to consider how well the selected indices perform under a range of conditions, and whether Sphagnum has a significant impact on the relationships tested. We found that both water indices tested (NDWI and fWBI) were sensitive to the water content changes in Sphagnum moss in the laboratory, and there was little difference between them. Most of the vegetation indices tested (the NDVI, EVI, SIPI and CIm)
\end{abstract}

Kirsten Lees was part funded by a studentship from The James Hutton Institute, and part funded by the Natural Environment Research Council (NERC) SCENARIO DTP (Grant number: NE/L002566/1). Tristan Quaife was funded by the NERC National Centre for Earth Observation (NCEO; Grant number NE/R016518/1). Myroslava Khomik and Rebekka Artz were funded by The Scottish Government Strategic Research Programme 20162021. Ritson is supported by the Engineering and Physical Sciences Research Council Twenty-65 project [Grant number EP/ N010124/1]. Much of the restoration work reported in this study was funded by EU LIFE, Peatland Action, HLF, and the RSPB.

Kirsten J. Lees was with the University of Reading at the time of this work, and is now with the University of Exeter, Laver Building, Streatham Campus, Exeter, EX4 4QE, UK (K.Lees@exeter.ac.uk).

Rebekka R.E. Artz is with the James Hutton Institute, Craigiebuckler, Aberdeen, AB15 8QH, Scotland.

Myroslava Khomik is with the University of Waterloo, 200 University Avenue West, Waterloo, ON, N2L 3G1, Canada.

Joanna M. Clark is with University of Reading, Whiteknights, Reading, RG6 6AB, UK.

Jonathan Ritson is with Imperial College London, SW7 2A7, UK

Mark H. Hancock and Neil R. Cowie are with the Royal Society for the Protection of Birds, Centre for Conservation Science, Edinburgh, EH12 9DH, UK.

Tristan Quaife is with the National Centre for Earth Observation, Department of Meteorology, University of Reading, Whiteknights Earley Gate, Reading, RG6 6BB, UK. were found to have a strong relationship with GPP both in the laboratory and in the field. The NDVI and EVI are useful for large-scale estimation of GPP, but are sensitive to the proportion of Sphagnum present. The CIm is less affected by different species proportions and might therefore be the best to use in areas where vegetation species cover is unknown. The PRI is shown to be best suited to small-scale studies of single species.

Index Terms - Hyperspectral Data, Vegetation and Land Surface, Optical Data, Multispectral Data

\section{INTRODUCTION}

PEATLANDS are an important ecosystem for the sequestration and storage of carbon, and also for supporting biological diversity [1]. Peatlands around the world store approximately a third of the world's soil carbon [2], [3], as within the waterlogged environment of peat substrates decomposition is limited and so organic matter is retained. Many peatlands have, however, been subject to deleterious management schemes, including drainage, commercial harvesting, overgrazing, planting for commercial forestry, and burning [4], [5]. These processes can lower the water table and increase bare peat surfaces, leaving them vulnerable to drought and its subsequent effects on photosynthesis of peatland vegetation, and consequently carbon sequestration.

Policy makers are now beginning to see peatland carbon storage as useful for mitigating climate change, and peatland restoration is being encouraged [6]. It is therefore important to develop cost-effective methods of assessing peatland condition and carbon sequestration. Spectral information from peatland vegetation can be used to remotely estimate the condition and carbon fluxes of peatlands [7]. Spectral indices, including those used in this study, have been shown to correlate with both moisture content and carbon fluxes of peatland vegetation [8]-[13]. Vegetation indices can be used to estimate plant health and photosynthesis, whilst water indices are useful proxies for moisture. These indices can be used alone to detect changes in either GPP or water content, or in combination for more complex analysis of peatland condition.

Sphagnum moss is a key genus in peatland formation, and its presence is an indication of good blanket bog condition [14]. Peat-forming plants such as Sphagnum are well adapted 
to the wet environment of blanket bogs, and grow less well when water tables are low [9], [11], [15]. Many Sphagnum species have an optimum water content of approximately twenty times their dry weight, and have been shown to decrease photosynthesis as moisture content is reduced [16][18]. As Sphagnum dries it experiences bleaching, which affects the spectral reflectance and can be detected by vegetation indices [16], [19], [20].

Hyperspectral data can be used to calculate vegetation indices which precisely align with specific plant functions, such as the Photochemical Reflectance Index (PRI) which corresponds to the xanthophyll photochemical protective mechanism. These newer indices require data which is more expensive and harder to obtain than the data needed by older indices such as the Normalised Difference Vegetation Index (NDVI). This study tests the accuracy and reliability of both hyperspectral and broad-band indices as proxies for water content and photosynthesis under a range of field and laboratory conditions. Pure Sphagnum samples were considered in the laboratory, and mixed peatland species in the field.

All the indices selected for this study have been shown to correlate with peatland vegetation Gross Primary Productivity (GPP), some during drought studies in the laboratory, and some in the field [9], [11], [13]. The current article builds on these previous works by testing successful indices against direct measurements of water content and GPP in both pure Sphagnum and mixed peatland vegetation, under a broad range of conditions including extreme water limitation.

Two water indices and three plant function indices were studied. The two water indices were: the hyperspectral floating Water Band Index (fWBI) which considers the water absorption feature between 930 and $980 \mathrm{~nm}$; and the broadband Normalised Difference Water Index (NDWI) which uses the difference between NIR (near infrared) and SWIR (shortwave infrared) to assess water content.

The broad-band plant function indices were the Normalised Difference Vegetation Index (NDVI) and the Enhanced Vegetation Index (EVI). These both focus on the difference between the red and NIR zones of the reflectance spectrum, and the EVI also includes the blue band to correct for atmospheric aerosols. The hyperspectral plant function indices included the Photochemical Reflectance Index (PRI) which is sensitive to the xanthophyll photoprotective mechanism; the Structure Insensitive Pigment Index (SIPI) which considers the chlorophyll/carotenoid ratio; and the modified Chlorophyll Index (CIm) which focuses on the red-edge (see Tables I and II).

Our work here aims to make a thorough examination of the selected indices to determine which give the best results in peatland environments. To do this we include both a laboratory study of replicate samples of pure Sphagnum moss cushions which were subjected to a long (80 days) period of drought, and a field study carried out over three different sites of mixed peatland species during the growing season. Our objectives were to determine (1) how strongly the selected indices correlate with water content and GPP, and (2) whether the relationships between selected indices, water content, and GPP are affected by the presence of Sphagnum compared to

TABLE I

BANDS

\begin{tabular}{|c|c|c|c|c|c|}
\hline Band & $\begin{array}{l}\text { Wavelengths } \\
\text { averaged in } \\
\text { this study }\end{array}$ & MODIS & $\begin{array}{l}\text { Landsat } \\
8\end{array}$ & VIIRS & $\begin{array}{l}\text { Sentinel- } \\
\text { 2A (central } \\
\text { wavelength } \\
\text { /band } \\
\text { width) }\end{array}$ \\
\hline Blue & $\begin{array}{l}450 \text { to } 515 \\
\mathrm{~nm}\end{array}$ & $\begin{array}{l}\text { Band } 3 \\
\text { (459 to } \\
479 \mathrm{~nm})\end{array}$ & $\begin{array}{l}\text { Band } 2 \\
(450 \text { to } \\
512 \mathrm{~nm})\end{array}$ & $\begin{array}{l}\text { M3 } \\
\text { (478 to } \\
498 \\
\mathrm{~nm}) \\
\end{array}$ & $\begin{array}{l}\text { Band 2 } \\
\text { (447.6 to } \\
545.6 \mathrm{~nm})\end{array}$ \\
\hline Red & $\begin{array}{l}630 \text { to } 680 \\
\mathrm{~nm}\end{array}$ & $\begin{array}{l}\text { Band } 1 \\
\text { (620 to } \\
670 \mathrm{~nm})\end{array}$ & $\begin{array}{l}\text { Band } 4 \\
\text { (636 to } \\
673 \mathrm{~nm})\end{array}$ & $\begin{array}{l}\text { M6 } \\
\text { (662 to } \\
682 \\
\mathrm{~nm}) \\
\end{array}$ & $\begin{array}{l}\text { Band } 4 \\
\text { (645.5 to } \\
683.5)\end{array}$ \\
\hline NIR & $\begin{array}{l}841 \text { to } 876 \\
\text { nm } \\
\text { (NDWI)/845 } \\
\text { to } 885 \mathrm{~nm} \\
\text { (NDVI \& } \\
\text { EVI) }\end{array}$ & $\begin{array}{l}\text { Band } 2 \\
\text { (841 to } \\
876 \mathrm{~nm})\end{array}$ & $\begin{array}{l}\text { Band 5 } \\
\text { (851 to } \\
879 \mathrm{~nm})\end{array}$ & $\begin{array}{l}\text { I2 }(846 \\
\text { to } 885 \\
\text { nm) }\end{array}$ & $\begin{array}{l}\text { Band 8A } \\
\text { (848.3 to } \\
881.3)\end{array}$ \\
\hline SWIR & $\begin{array}{l}1628 \text { to } 1652 \\
\mathrm{~nm}\end{array}$ & $\begin{array}{l}\text { Band } 6 \\
(1628 \text { to } \\
1652 \\
\mathrm{~nm})\end{array}$ & $\begin{array}{l}\text { Band } 6 \\
\text { (1566 to } \\
1651 \\
\mathrm{~nm})\end{array}$ & $\begin{array}{l}\text { I3 } \\
(1580 \\
\text { to } 1640 \\
\mathrm{~nm})\end{array}$ & $\begin{array}{l}\text { Band } 11 \\
(1542.2 \text { to } \\
1685.2)\end{array}$ \\
\hline
\end{tabular}

The averaged bands used in this study for broad-band indices compared to the bands of commonly used satellites MODIS, Landsat, VIIRS and Sentinel2 .

TABLE II

INDICES

\begin{tabular}{|c|c|c|c|}
\hline Index & Equation & $\begin{array}{l}\text { Relevant } \\
\text { references }\end{array}$ & $\begin{array}{l}\text { Broad-band or } \\
\text { hyperspectral }\end{array}$ \\
\hline $\begin{array}{l}\text { Floating Water } \\
\text { Band Index } \\
\text { (fWBI) }\end{array}$ & $\begin{array}{l}\mathrm{fWBI}=\mathrm{R}_{920} / \\
\min \left(\mathrm{R}_{930-980}\right)\end{array}$ & $\begin{array}{l}\text { Strachan et } \\
\text { al., 2002; } \\
\text { Harris, 2008 } \\
\end{array}$ & Hyperspectral \\
\hline $\begin{array}{l}\text { Normalised } \\
\text { Water Difference } \\
\text { Index (NDWI) }\end{array}$ & $\begin{array}{l}\mathrm{NDWI}=\left(\mathrm{R}_{\mathrm{NIR}}\right. \\
\left.-\mathrm{R}_{\mathrm{SWIR}}\right) /\left(\mathrm{R}_{\mathrm{NIR}}\right. \\
\left.+\mathrm{R}_{\mathrm{SWIR}}\right)\end{array}$ & Gao, 1996 & Broad-band \\
\hline $\begin{array}{l}\text { Normalised } \\
\text { Difference } \\
\text { Vegetation Index } \\
\text { (NDVI) }\end{array}$ & $\begin{array}{l}\mathrm{NDVI}=\left(\mathrm{R}_{\mathrm{NIR}}\right. \\
\left.-\mathrm{R}_{\mathrm{red}}\right) /\left(\mathrm{R}_{\mathrm{NIR}}+\right. \\
\left.\mathrm{R}_{\mathrm{red}}\right)\end{array}$ & $\begin{array}{l}\text { Rouse et al., } \\
1974\end{array}$ & Broad-band \\
\hline $\begin{array}{l}\text { Enhanced } \\
\text { Vegetation Index } \\
\text { (EVI) }\end{array}$ & $\begin{array}{l}\mathrm{EVI}=2.5 \times(( \\
\left.\mathrm{R}_{\mathrm{NIR}}-\mathrm{R}_{\text {red }}\right) /( \\
\mathrm{R}_{\mathrm{NIR}}+6 \times \mathrm{R}_{\text {red }}+ \\
\left.\left.7.5 \times \mathrm{R}_{\text {blue }}+1\right)\right)\end{array}$ & $\begin{array}{l}\text { Didan et al., } \\
2015\end{array}$ & Broad-band \\
\hline $\begin{array}{l}\text { Photochemical } \\
\text { Reflectance } \\
\text { Index (PRI) }\end{array}$ & $\begin{array}{l}\mathrm{PRI}=\left(\mathrm{R}_{531}-\right. \\
\left.\mathrm{R}_{570}\right) /\left(\mathrm{R}_{531}+\right. \\
\left.\mathrm{R}_{570}\right)\end{array}$ & $\begin{array}{l}\text { Gamon et al. } \\
1992 ; \\
\text { Penuelas et } \\
\text { al., 1995; } \\
\text { Van Gaalen } \\
\text { et al., } 2007 \\
\end{array}$ & Hyperspectral \\
\hline $\begin{array}{l}\text { Structurally } \\
\text { Insensitive } \\
\text { Pigment Index } \\
\text { (SIPI) }\end{array}$ & $\begin{array}{l}\text { SIPI }=\left(\mathrm{R}_{800}-\right. \\
\left.\mathrm{R}_{445}\right) /\left(\mathrm{R}_{800}-\right. \\
\left.\mathrm{R}_{680}\right)\end{array}$ & $\begin{array}{l}\text { Penuelas et } \\
\text { al., 1995; } \\
\text { Harris, 2008 }\end{array}$ & Hyperspectral \\
\hline $\begin{array}{l}\text { Modified } \\
\text { Chlorophyll } \\
\text { Index }\end{array}$ & $\begin{array}{l}\mathrm{CIm}=\left(\mathrm{R}_{750}-\right. \\
\left.\mathrm{R}_{705}\right) /\left(\mathrm{R}_{750}+\right. \\
\left.\mathrm{R}_{705}-2 \times \mathrm{R}_{445}\right) \\
\end{array}$ & $\begin{array}{l}\text { Sims and } \\
\text { Gamon, } 2002\end{array}$ & Hyperspectral \\
\hline
\end{tabular}

The water indices and vegetation indices used in this study, their equations and relevant references (for the development of the equations in the form used in this study). In the equations given in this section ' $R$ ' subscripted by a number is a single wavelength in a mono-spectral index. ' $R$ ' subscripted by a band name (Table I) indicates a band. Colour band equivalents are given in Table I and shown in Fig. 2.

other peatland species. 


\section{METHODS}

\section{A. Field Site}

The field site for this study was the Forsinard Flows RSPB reserve (https://www.rspb.org.uk/reserves-andevents/reserves-a-z/forsinard-flows/) in North Scotland (approx. 58.36, -4.00 to 58.45, -3.70 WGS84, see Fig. 1). This site is part of the $4,000 \mathrm{~km}^{2}$ Flow Country blanket bog; Europe's largest blanket bog [21], of which approximately $1,300 \mathrm{~km}^{2}$ is protected under EU Habitats and Birds Directives. The area includes extensive blanket bogs with only minor human impacts [22] and lightly grazed by deer. These areas are referred to here as 'near-natural'. Other areas of the Flow Country were planted with non-native conifers for commercial forestry, and in many areas, including in Forsinard Flows, the trees have been felled and the sites are now undergoing restoration. In many of the restoration sites the landscape still shows distinctive furrows and ridges from the drainage ditches created for forestry.

The field study used three sites within the Forsinard Flows RSPB reserve. Two of these were ex-forestry sites on deep peat, being restored towards blanket bog [23]: Lonielist, which was felled in 2003-04, and Talaheel, which was felled in 1998 and was subject to further hydrological management in 2015/16 whereby plough furrows were dammed. The third site was at Cross Lochs [24]; this area of intact bog was considered to be a near-natural control.

The nearest meteorological station with daily data available was Altnaharra, approximately $35 \mathrm{~km}$ south-west of the Forsinard Flows reserve (see Fig. 1). This has been used for weather data in Section III B 1.

\section{B. Laboratory experiment}

A laboratory experiment was used to measure the relationships between the selected indices, water content, and GPP in pure Sphagnum samples. Water limitation and drought stress was used to generate a range of water contents and GPP values to assess the correlations with the water and vegetation indices. This laboratory experiment is also described in Lees et al [16], in which the focus is on the relationship between

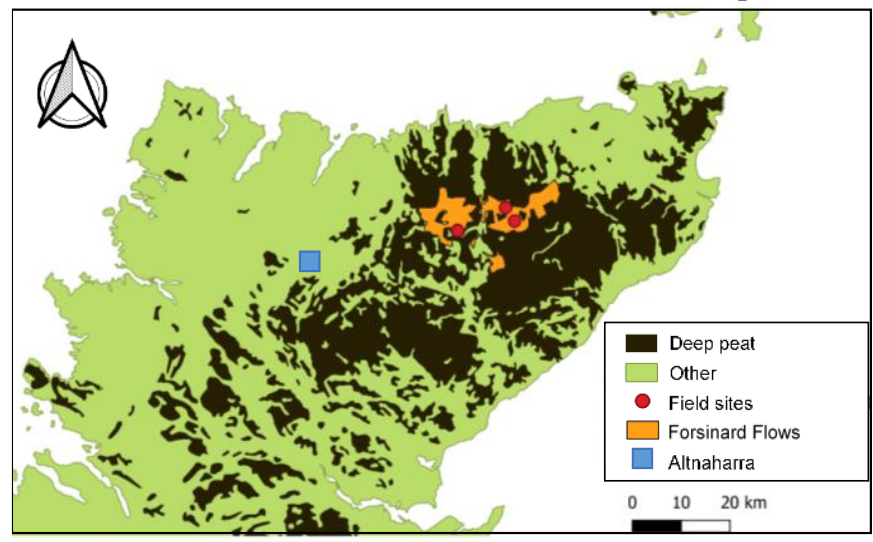

Fig. 1. Map of the northern Scottish mainland showing peatland areas in dark brown [51], the Forsinard Flows RSPB reserve in orange (European Environment Agency, 2017), the three field sites as red circles, and the meteorological station at Altnaharra as a blue square. The peatland dominated landscapes in this area are referred to as the 'Flow Country'. water content and GPP, and the interaction with the reflectance spectra as a whole. The current study uses the same data to calculate the selected indices.

Two Sphagnum species, S. capillifolium and S. papillosum, were selected. Both species are commonly found at our study sites but prefer different microhabitats. S. capillifolium is hummock-forming, red to green in appearance, with hemispherical capitula [25]. S. papillosum is green to yellowbrown, prefers wetter conditions and grows in carpets [16], [25]. S. capillifolium is also more tolerant to disturbance than $S$. papillosum, and is one of the first species to re-colonise areas of peatland undergoing restoration [23].

Twenty samples of each species were collected from the Forsinard Flows RSPB reserve in PVC tubing $6 \mathrm{~cm}$ deep and $10 \mathrm{~cm}$ diameter during September 2016. The samples were kept moist and transported from the field to the laboratory in a coolbox over a period of 3 days. Once in the laboratory the samples were placed in 1 litre, straight-sided, clear polycarbonate jars and maintained in a growth cabinet (Panasonic MLR-352H-PE) on a 12-hour day and 12-hour night cycle (similar to conditions in the field during the collection period in September). During the day the growth cabinet was kept at maximum light levels $(20,000 \mathrm{~lx}), 15^{\circ} \mathrm{C}$, and $70 \%$ relative humidity (slightly lower than the average at the site to aid drying of samples). At night the cabinet was dark, at $5^{\circ} \mathrm{C}$, and the humidity was unregulated.

When the samples first arrived in the laboratory they were inundated with deionised water (for consistency with previous studies eg. [26], [27]) and the excess drained off manually to bring them to saturation. After a week-long acclimatisation period, during which the samples were regularly watered (also with deionised water) to maintain saturation, four samples of each species were subjected to total drought for 80 days. This length of drought would be very unlikely in the field but was used to analyse complete desiccation. Three times per fortnight (every 4-5 days) the $\mathrm{CO}_{2}$ fluxes of all the samples were measured. The flux measurements were taken using a LICOR-8100 (LICOR Inc., Lincoln, Nebraska, USA) and a clear polycarbonate custom-built chamber $(13 \mathrm{~cm}$ tall, $11 \mathrm{~cm}$ diameter). Each sample was brought out of the growth cabinet and placed under a high-pressure sodium growth lamp (Philips Belgium 9M SON-T-AGROO 400; 55,500 lm) in a laboratory in order to keep light levels as constant as possible. The clear chamber was placed over the sample using a foam seal and a 90 second measurement taken of Net Ecosystem Exchange (NEE) (after an acclimatisation period of $20 \mathrm{~s}$ ). A blackout cloth cover was then placed over the chamber, and the measurement taken again to gather net respiration data (Rtot). The Gross Primary Productivity (GPP) was calculated as the difference between the light and dark chamber results. Four weeks into the study, we observed that variation in ambient lighting affected our results. Therefore, from that point onwards we measured photosynthetically active radiation (PAR) during each experiment. This allowed us to correct later results. Earlier results were corrected by estimating PAR from measurement time (see Appendix). 
Samples were weighed three times a week before and after watering throughout the experiment. At the end of the experiment the samples were dried in a laboratory oven at $70^{\circ} \mathrm{C}$ for 72 hours, and the dry weights measured to retrospectively calculate moisture content. This method assumes there was no significant growth in the Sphagnum samples during the experimental period. All moisture contents are given in grams fresh weight/grams dry weight $(\mathrm{g} / \mathrm{g})$.

Spectral reflectance was measured using a Ger3700 spectrometer (Geophysical and Environmental Research Corp., $1999 ; 350 \mathrm{~nm}$ to $2,500 \mathrm{~nm}$; high resolution) mounted in a dark room with a single constant light source $(1000 \mathrm{~W}$ highintensity halogen lamp at an angle of $45^{\circ}$ and a distance of 0.5 $\mathrm{m})$. Each sample was placed under the spectrometer and a measurement taken of the central area of the sample (approximately $4 \mathrm{~cm}$ diameter); the sample was then rotated by approximately $120^{\circ}$ for a second measurement and rotated again for a third measurement. The average of these three spectra was taken to compensate for potential structural effects. Reference spectra, using a spectralon panel, were taken between samples and used to convert the measured radiances to reflectances [28].

\section{Field experiment}

This experiment was designed to assess how the selected indices, water content, and GPP vary spatially and temporally across the growing season of a typical peatland with a mix of vegetation species. Measurement collars included a mix of peatland species including the two Sphagnum species used in the laboratory experiment.

All three sites (Lonielist, Talaheel, and Cross Lochs) had an Eddy Covariance (EC) tower installed. At each of the sites eight plots were located along two perpendicular transects. The transects were arranged within the footprint of the EC towers according to the size of the tower footprint and the dominant wind directions [29]. At Lonielist the main transect was $80 \mathrm{~m}$ and the secondary transect was $60 \mathrm{~m}$, with all plots $20 \mathrm{~m}$ apart. At Talaheel the transects were $100 \mathrm{~m}$ and $75 \mathrm{~m}$ with the plots $25 \mathrm{~m}$ apart, and at Cross Lochs the transects were $120 \mathrm{~m}$ and $90 \mathrm{~m}$ with plots $30 \mathrm{~m}$ apart.

At each plot two PVC collars (24 cm in diameter) were located one on higher ground (ridges in the restored sites, hummocks at Cross Lochs) and one on lower ground (in the furrows at the restored sites, lawns at Cross Lochs). The vegetation within the collars included the Sphagnum mosses used in the laboratory experiment, but also other mosses, sedges Cyperaceae, and dwarf shrubs Ericaceae. The percentage cover of each species within the collars was estimated visually and used to assess which collars were Sphagnum-dominated (over 50\% cover). The Lonielist site set-up included manually monitored dipwells used to record WTD [30] paired with each of the collars. Measurements, including $\mathrm{CO}_{2}$ fluxes, spectral reflectance, and environmental conditions, were taken once a month during the 2017 growing season March to September.

$\mathrm{CO}_{2}$ flux measurements were taken using a LICOR-8100 (LICOR Inc., Lincoln, Nebraska, USA) and clear Perspex custom-built chambers ( $24 \mathrm{~cm}$ diameter, $30 \mathrm{~cm}$ height). Small battery-operated fans were installed within the chambers to circulate the air. Light (NEE) and dark (Rtot) measurements were taken as consecutive measurements, sealing to the chamber with rubber mastic (Terostat). Each measurement was taken for five minutes, with a 20 second pre-measurement period for stabilisation.

Spectral measurements in the field were taken using a handheld SVC HR-1024 spectroradiometer ( $350 \mathrm{~nm}$ to 2500 $\mathrm{nm}$; high resolution) mounted on a monopod and held approximately $1 \mathrm{~m}$ from the surface. Three measurements were taken of the vegetation within each collar, rotated between each measurement by approx. $90^{\circ}$ whilst avoiding shadow creation, to minimise structural effects. A spectralon reference panel was used before each measurement to correct for changing light conditions.

Photosynthetically Active Radiation (PAR) was measured continuously during the clear chamber measurement period using a sensor planted in the peat outside the chamber (within $20 \mathrm{~cm}$ ) and connected to the Licor-8100. Soil moisture was measured using a moisture probe (ThetaKit moisture meter, 6 $\mathrm{cm}$, Dynamax) within $20 \mathrm{~cm}$ of the chamber, during the flux measurements. The dipwells at Lonielist were manually monitored. Soil temperature was measured at $5 \mathrm{~cm}$ and $15 \mathrm{~cm}$ from the moss surface (lollipop thermometer, Fisherbrand, accurate to $\pm 1^{\circ} \mathrm{C}$ ) and surface temperature inside the chamber at the start and end of each measurement.

\section{Indices}

The indices used in this study were all calculated using reflectance values averaged over a range of wavelengths which can be compared to those used by different satellites (see Table I and Fig. 2).

\section{1) Water Indices}

The water indices used in this study are shown in Table II. The fWBI was calculated following Strachan et al. (2002) on the rationale that the water absorption feature is not static but shifts between 930 and $980 \mathrm{~nm}$. This is compared to a reference wavelength at $920 \mathrm{~nm}$ as used by Harris (2008). The NDWI was calculated using the NIR and SWIR ranges. The SWIR is affected by both the vegetation chlorophyll and the water content, whilst the NIR is not affected by water content.

\section{2) Plant Function Indices}

The vegetation indices used in this study are shown in Table II. The NDVI is a broad-band index which focuses on the difference between the red light absorbed by healthy vegetation and the NIR reflected. The equation for EVI follows the calculation of the MOD13 product [32], and is less sensitive to atmospheric aerosols and saturation over dense canopies than the NDVI [33].

The PRI calculation follows Gamon et al. [34] and Penuelas et al. [35].The PRI works on the principle that $531 \mathrm{~nm}$ is the wavelength at which the xanthophyll photoprotective mechanism can be detected, and is therefore a direct measure of light use efficiency in plants [34]. $570 \mathrm{~nm}$ was used as the 


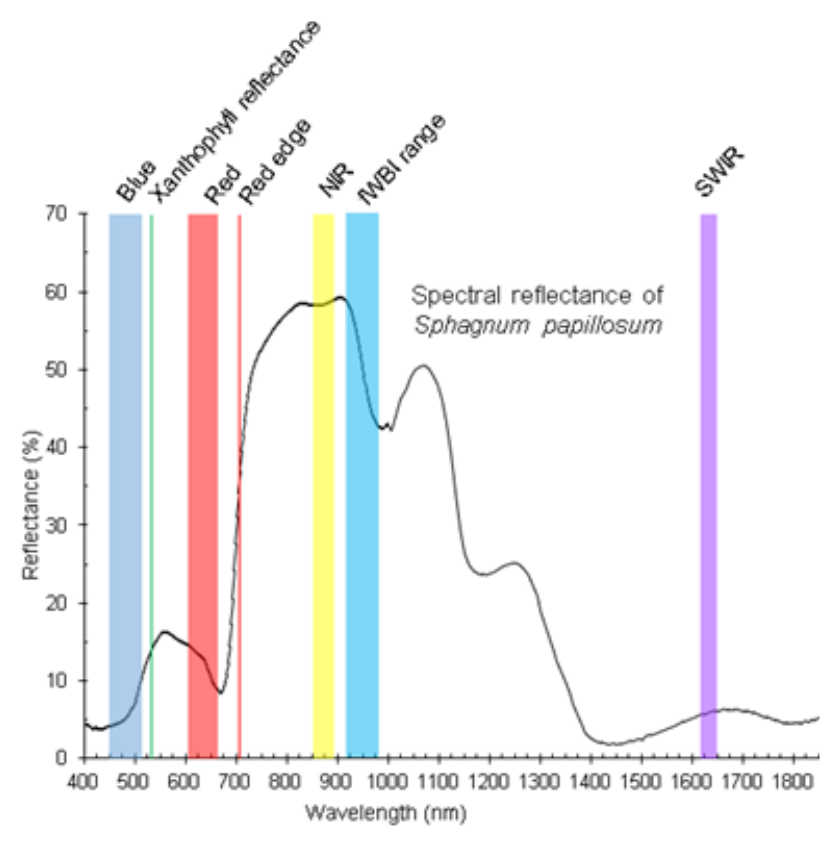

Fig. 2. Spectral reflectance graph of a healthy sample of S. papillosum, taken during the laboratory experiment, showing the ranges and wavelengths used by the indices in this study.

reference wavelength following Van Gaalen et al. [11].

The SIPI developed by Penuelas et al. [35] considers the chlorophyll/ carotenoid ratio, which Harris [9] found to increase as photosynthesis decreases.

The CIm makes use of the red-edge principle, which considers the movement of the boundary between the red absorption zone and the NIR reflectance region. Adding $\mathrm{R}_{445}$ to the equation is a measure of surface reflectance not affected by chlorophyll or carotenoids, to compensate for generally high leaf reflectance [36].

\section{E. Statistical Analysis}

\section{1) Laboratory Analysis}

In order to create composite models and to perform comparative statistics, the laboratory data for all samples were binned into twelve groups of equal size using the water content for water indices analysis and the GPP for vegetation indices analysis (using R package ggplot2, [37]). For the water indices analysis the two species were binned separately, as the relationship to the water indices was found to be species dependent in a mixed effects model. A value of 1 was subtracted from the fWBI values to create an index with a starting value of 0 , and for NDWI a value of 0.1 was subtracted for the same reason.

The relationship between both water indices and water content (binned data for each species) was fitted to a linear model and an alternative Gompertz function model, and Akaike information criterion (AIC) was used to compare the fit of the two models. Gompertz functions are similar to logistic growth functions, but do not have the assumption of centrality and symmetry in the point of inflection [38].

To assess the relationships between each vegetation index and GPP in the laboratory study, both linear and polynomial regression models of $2^{\text {nd }}$ order were first assessed using the data averaged within 12 GPP bins of equal count. AIC was used to assess the relative quality of each model. For all five vegetation indices tested, a linear model was found to be better than a polynomial model. A linear mixed model including species and sample was therefore fitted to the data for each index. The Breusch-Pagan test for heteroscedasticity (package lmtest, [39]) was applied to the models, and if heteroscedasticity was present a Box-Cox transformation (package EnvStats, [40]) was applied to the index data series.

\section{2) Field Analysis}

A fitted logarithmic model (calculated using all field data combined) was used to correct for the effects of PAR $\left(\mu \mathrm{mol} / \mathrm{m}^{2} / \mathrm{s}\right)$ on GPP in the field:

GPPcorrected $=$ GPP $-0.9 \times \ln (\mathrm{PAR})+2.51$

Heinemeyer et al. (2013) found that the relationship between PAR outside and inside a similar Perspex chamber was linear, with a $34 \%$ decrease due to the chamber. We have assumed that a linear relationship between internal and external PAR is true in this study, and so the logarithmic correction applied to the GPP is the same in both cases.

For the field measurements of GPP, a linear model incorporating GPP and month as independent variables, and assessing the interaction between them, was used.

All statistical work was done in R [42]. Data collected and analysed in this study are archived in the NERC EIDC [43].

\section{3) Field and laboratory comparison}

Differences between Sphagnum dominated and non-Sphagnum dominated collars were assessed using a two-way ANOVA including month as a factor, followed by Tukey post-hoc testing. Linear models were used to test interactions.

\section{RESULTS}

\section{A. Laboratory Results}

\section{1) Moisture Content}

The changes in water content and the NDWI across the experimental period are shown in Fig. 3. The water content decreased steadily across the experimental period until about day 40, when the decrease slowed. Meanwhile the NDWI had the most rapid period of decrease between approximately day 20 and day 40. The two water indices (fWBI and NDWI) had relatively low sensitivity at the lower end of the water content curve and saturated early at the high end. (Fig. 4). For both indices, the relationship with water content for the $S$. capillifolium samples fitted well to Gompertz functions, with little variation of the indices at high and low moisture contents and a rapid change between (see Fig. 4A and 4C). S. papillosum, however, did not conform as consistently to this pattern for both indices. The NDWI and fWBI of $S$. papillosum samples continued to increase, albeit at a slower rate, whereas the fitted Gompertz functions predict an upper limit. In general, the relationship between indices and water 


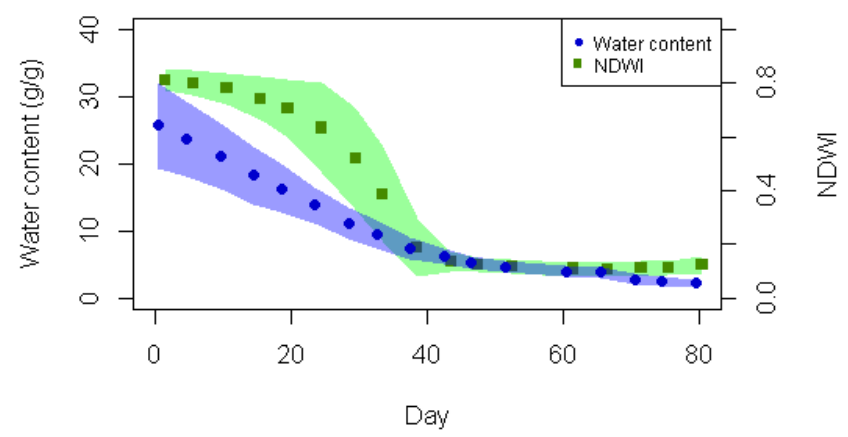

Fig. 3. The change in average water content and NDWI of all 8 samples over the 80 day experimental drought period, with standard deviation of values shown as colored areas. The two datasets are offset by half a day in this plot (actually taken within 10 hours of each other) so both are visible. The change in fWBI is similar although not shown here.

content showed more scatter for S. papillosum.

\section{2) $G P P$}

The linear mixed model for the NDVI relationship with GPP was highly significant $\left(\mathrm{p}<0.001, \mathrm{R}^{2}=0.38\right)$ and showed no significant effects or interactions of species or sample (see Fig. 5A). The same was true for the EVI $\left(\mathrm{p}<0.001, \mathrm{R}^{2}=0.44\right.$, see Fig. 5B).

The model for the CIm showed heteroscedasticity, and so a Box-Cox transformation was applied to the dataset. The model

A

S. capillifolium

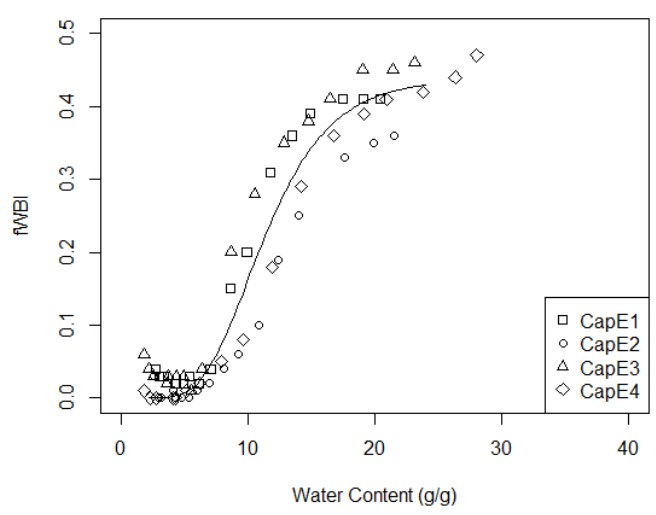

C

S. capillifolium

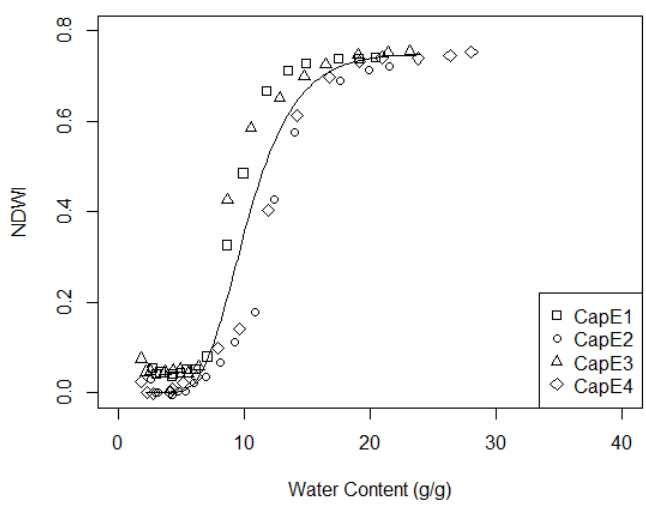

using transformed data was highly significant $(\mathrm{p}<0.001$, $\mathrm{R}^{2}=0.43$, see Fig. 5C) and showed no significant effects or interactions apart from an effect of sample 'CapE3' $(p<0.05)$. The SIPI model also required transformation, and the resulting model was also highly significant $\left(p<0.001, R^{2}=0.32\right.$, see Fig. 5D) with no effects or interactions other than an effect of 'CapE3' $(\mathrm{p}<0.05)$.

The PRI model also showed heteroscedasticity, and this was not improved by applying a Box-Cox transformation. The model showed a significant species effect, so we decided to fit the two Sphagnum species separately. A linear model was found to be the best option for the binned data of $S$. capillifolium alone. The linear mixed model, including GPP and sample, for $S$. capillifolium was highly significant $\left(p<0.001, R^{2}=0.50\right)$, and did not show heteroscedasticity. It did show a significant effect for sample 'CapE4', and also a significant interaction of 'CapE4' with GPP. S. papillosum, however, did not conform well to a linear model. The binned data showed a significant $(\mathrm{p}<0.05)$ polynomial relationship (see Fig. 5E).

The GPP response of these two different Sphagnum species to the laboratory drought experiment is discussed in more detail in Lees et al. [16].

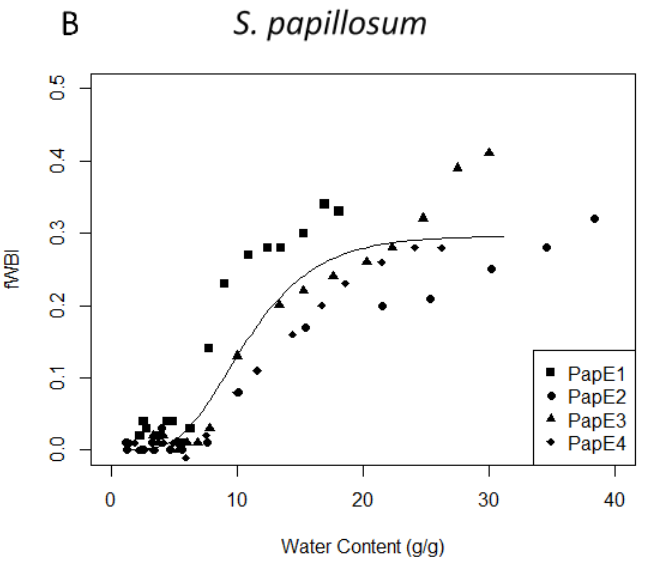

D S. papillosum

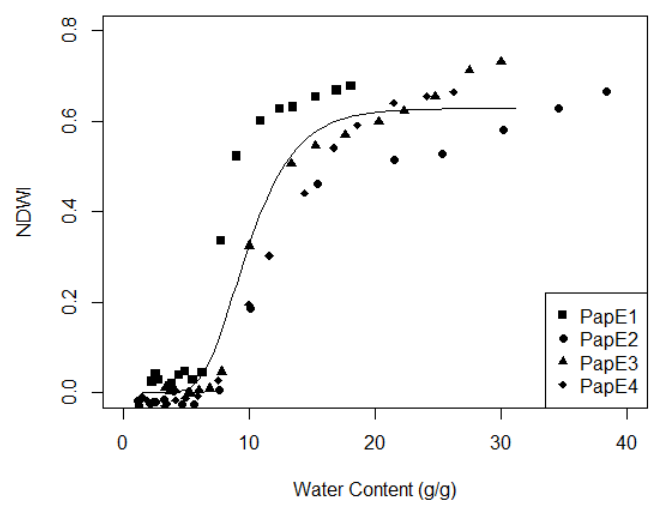

Fig. 4. A: Relationship between water content and fWBI for S. capillifolium samples. B: Relationship between water content and fWBI for S. papillosum. C: Relationship between water content and NDWI for $S$. capillifolium samples. D: Relationship between water content and NDWI for $S$. papillosum samples. Gompertz functions fitted using the binned water content data for each species are shown as lines to illustrate the relationships. 
A

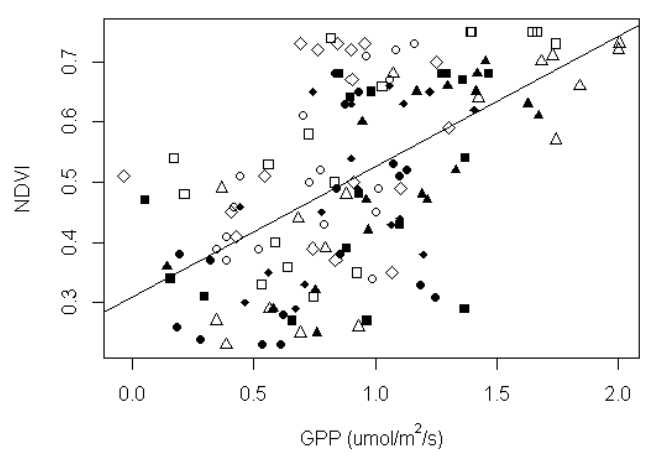

C

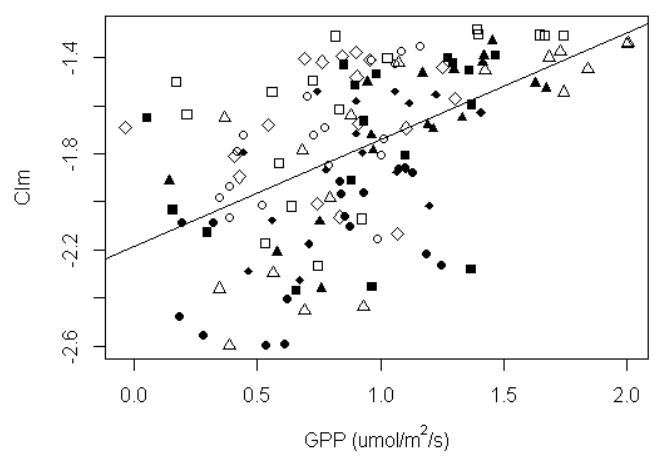

B
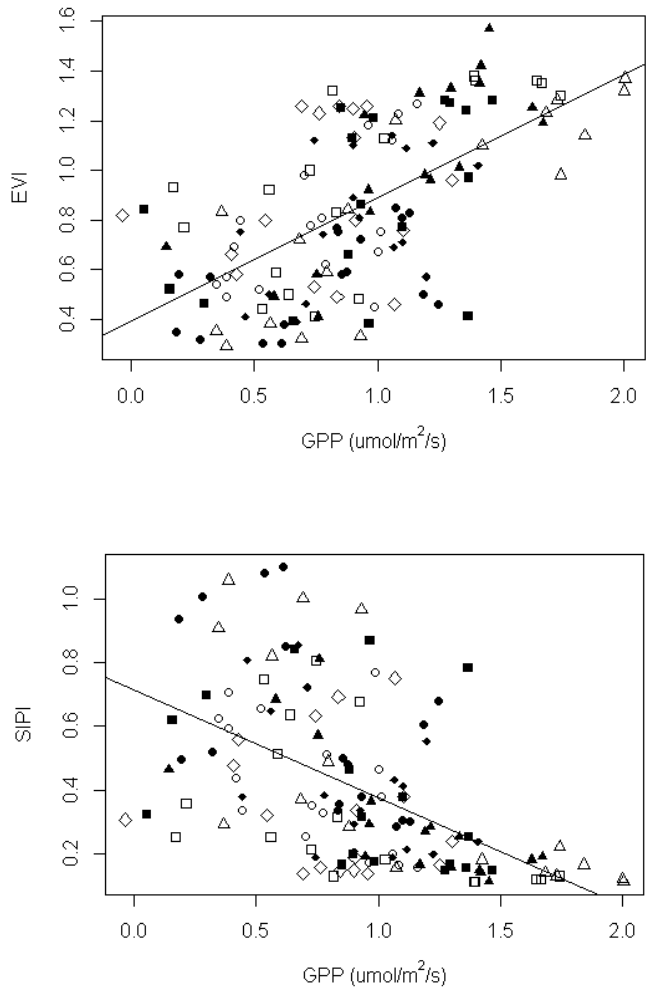

E

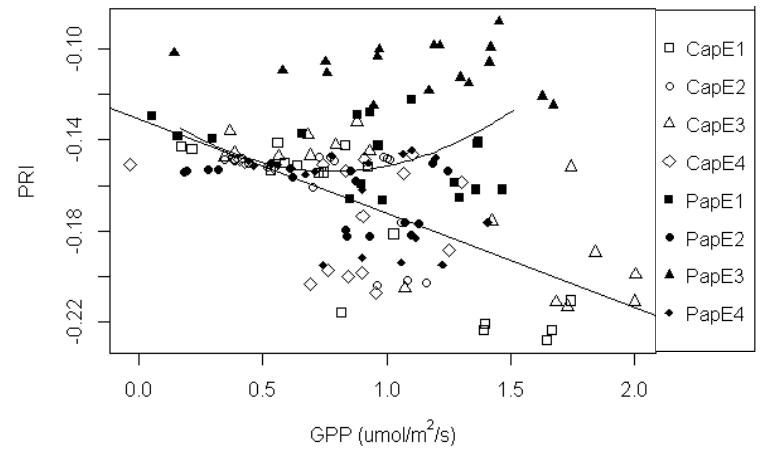

Fig. 5. Relationships between GPP and vegetation indices for the eight laboratory samples. The graphs showing CIm (C) and SIPI (D) use the transformed data. Black lines show the models fitted to averaged binned data. The graph showing PRI (E) includes the linear model for $S$. capillifolium, and the polynomial for $S$. papillosum. Black symbols are for S. papillosum, white symbols for S. capillifolium. Numbers in the legends refer to the individual samples.

\section{B. Field Results}

\section{1) Moisture Content}

Neither the soil moisture nor the WTD had a clear relationship with either of the two water indices (data not shown).

\section{2) $G P P$}

The mixed effects linear regression model for NDVI showed a significant relationship with GPP, and also a significant interaction between GPP and month in every month. This indicates that the slope of the relationship between GPP and NDVI varies across the seasons (see Fig. 6). The adjusted $\mathrm{R}^{2}$ of the model was $0.49(\mathrm{p}<0.001)$. The same model interactions were true of the EVI $\left(\mathrm{R}^{2} 0.54, \mathrm{p}<0.001\right)$, and the SIPI $\left(\mathrm{R}^{2} 0.48, \mathrm{p}<0.001\right)$.

The CIm regression model showed a strongly significant relationship with GPP, but fewer significant interactions with months. This suggests that the slope of the relationship between GPP and CIm is less affected by seasonality (month) than it is for the NDVI or EVI. The adjusted $\mathrm{R}^{2}$ of this model was $0.60(\mathrm{p}<0.001)$.

The regression model for PRI was significant $(\mathrm{p}<0.01)$, but showed no significant effects or interactions, and had a very small $\mathrm{R}^{2}$ value of 0.068 .

When each month was considered individually, the NDVI showed significant relationships with GPP for every month 


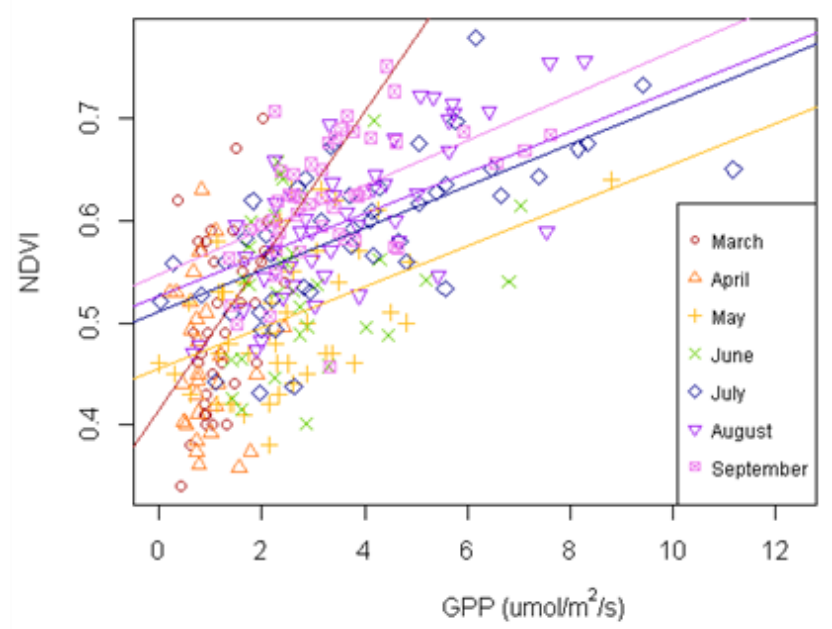

Fig. 6. Relationships between GPP and NDVI for each month in the field. Lines show the significant $(\mathrm{p}<0.05)$ linear models for each month in different colours.

apart from April and June (see Fig. 6); these two months had poor weather conditions which prevented full dataset collection. The linear model for March had a much steeper slope than the other months (0.073 compared to a range of 0.020 to 0.022 ). This pattern was also true of the EVI, CIm and SIPI.

\section{Field and Laboratory comparison \\ 1) Moisture Content}

The range of values seen in the field for the two water indices was towards the lower end of the range seen in the laboratory (monthly averages of 0.062 to 0.25 compared to measurement day averages of 0.11 to 0.81 for the NDWI). The field collars which were Sphagnum dominated (Sphagnum coverage of over 50\%), however, had higher average NDWI values than the non-Sphagnum dominated collars in every month except March, and the difference was significant at the $99 \%$ level in June, July, August, and September (see Fig. 7). The differences were similar for the fWBI.

\section{2) $G P P$}

Most of the tested vegetation indices also showed differences between the laboratory and the field experiments. NDVI values were lower in the field than the laboratory, but higher in the Sphagnum dominated collars than the nonSphagnum collars (although the differences were not clearly significant in any month) (see Fig. 7). The EVI showed the same patterns, and the SIPI and PRI showed similar but inverted differences (and the PRI had a significant difference between Sphagnum/non-Sphagnum collars at the 95\% level in September). Interestingly, the CIm showed almost no differences between the Sphagnum and non-Sphagnum dominated collars in the field, or between the field collars and the pure Sphagnum collars in the laboratory (see Fig. 7).

Linear models predicting the vegetation indices showed that there were no significant interactions between GPP and Sphagnum/non-Sphagnum.
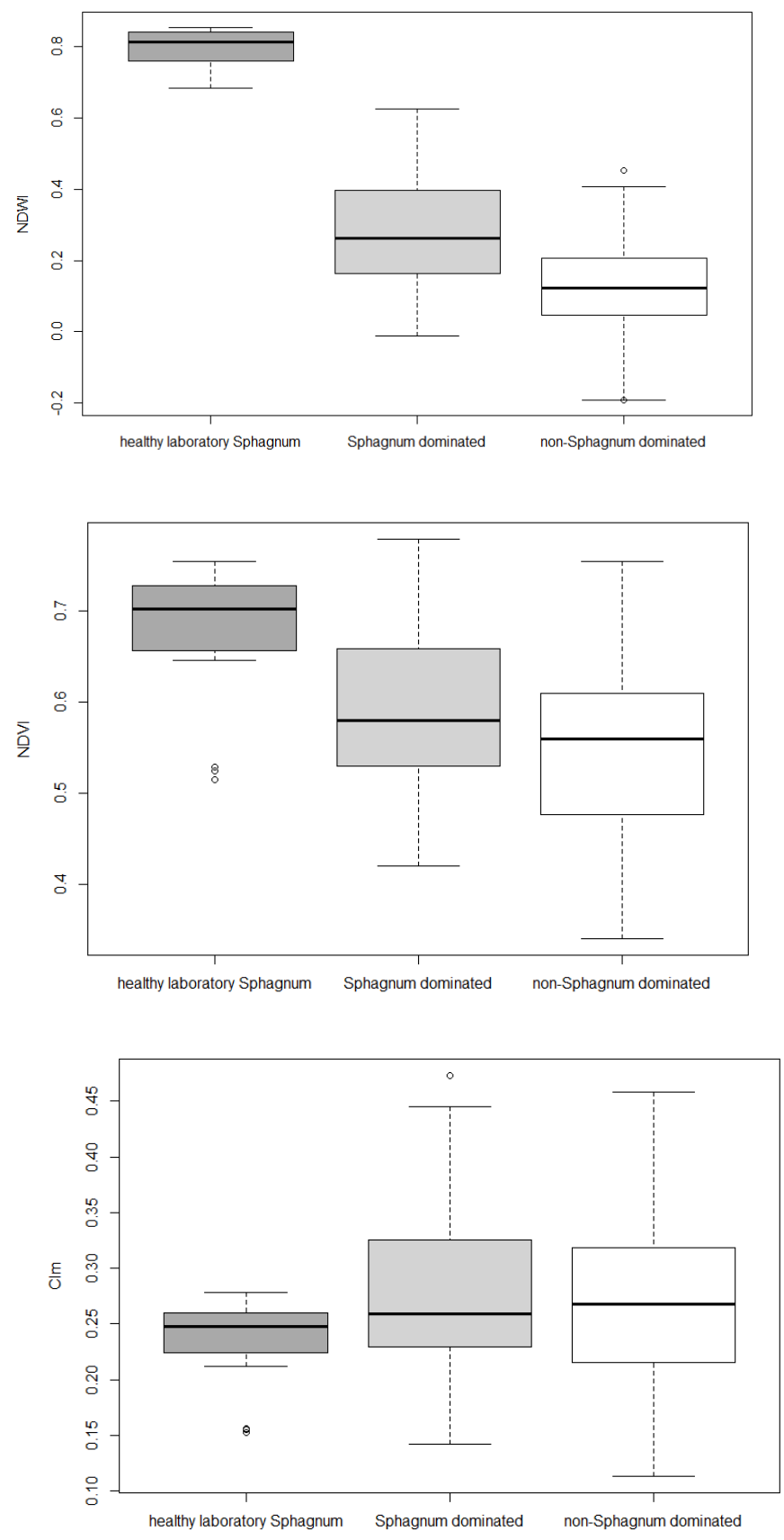

Fig. 7. Comparison of laboratory pure Sphagnum samples (first three measurement days before drought effects were observed, $n=24$ ) with Sphagnum dominated $(\mathrm{n}=56)$ and non-Sphagnum dominated field collars $(\mathrm{n}=246)$ (all months and sites). Top graph shows NDWI, middle NDVI, and bottom CIm.

\section{DISCUSSION}

\section{A. Moisture Content}

The results from these experiments showed that both water indices tested, the fWBI and NDWI, had positive correlations with moisture content in the laboratory study on pure Sphagnum samples. This agrees with previous studies [9], [11]-[13] that have also found good correlations between moisture content and water indices in Sphagnum species $(S$. 
teres; S. rubellum, S. fuscum, S. magellanicum, and S. fallax; S. pulchrum, S. tenellum, S. capillifolium, S. subnitens, and S. papillosum). Letendre et al. [13] calculated a Pearson's correlation coefficient of 0.77 for water content and the NDWI of four replicates of three different Sphagnum species, and higher correlations for each species considered separately. Within their study only $S$. fuscum showed a pattern similar to the Gompertz function (they did not use $S$. capillifolium or $S$. papillosum).

Van Gaalen et al. [11] found strong linear relationships between water content and the Water Band Index (a precursor of the fWBI) for three samples of different Sphagnum species. Their water content results were in the range of 5 to $20 \mathrm{~g} / \mathrm{g}$, however, and it was mainly beyond this range that our results showed saturation of the water index signals; a wider range of water contents might have shown a non-linear pattern.

In agreement with the current work, Letendre et al. [13] and Harris et al. [10] found that relationships between water indices (NDWI, Water Index (WI), Relative Depth Index (RDI), and two different formulations of fWBI, Moisture Stress Index (MSI), respectively) and water content were species specific. In this study we found that $S$. papillosum showed less clear saturation of the water indices signals at higher water contents, possibly because it prefers wetter microhabitats compared to S. capillifolium.

Statistical testing of the field data did not show any significant relationships between soil moisture or WTD and either of the two indices. Harris et al. [8] did find significant relationships between the fWBI and the moisture content in the top $6 \mathrm{~cm}$ (measured using a ThetaProbe), and between the fWBI and water table depth, at their study site at Cors Fochno, Wales. The relationship was particularly clear in their data from September 2002, when rainfall was less than half the average precipitation for the month. Meingast et al. [12] also found strong field relationships between water indices and soil moisture during a drought simulation experiment. This indicates that the relationship between soil moisture and water indices may be stronger when a larger range of water contents is included, and our study period was continuously wet as indicated by the SMD values that were negative for almost the entire growing season except a short period in May. It is only in this dryer May period that a decrease in water table depth and soil moisture, and also in both water indices, was observed. Future studies assessing the performance of these indices during drought periods in the field would be useful.

It is interesting that the field values from the two water indices were mainly in the lower part of the range seen in the laboratory study. This could suggest that the collars measured in the field were drier than the saturated Sphagnum samples, and is probably also indicative of the wider mix of vegetation that was present in the collars affecting the signal [12]. This is supported by the Sphagnum-dominated collars having higher NDWI values than the non-Sphagnum dominated collars. The optimum plant tissue water content for Sphagnum mosses is around twenty times their dry weight, but much less for other plants such as shrubs and sedges also present at our field sites [23], [44].
These results show that both the water indices considered in this study are very sensitive to vegetation water content, and there is minimal difference in performance between the two tested indices. This suggests that the broad-band NDWI which can be calculated from freely-available satellite data performs as well as the fWBI using hyperspectral data, similar to results found by Meingast et al. [12].

\section{B. $G P P$}

All the vegetation indices tested had some relationship with GPP in both the pure Sphagnum samples tested in the laboratory and the mixed peatland species in the field. The three indices with the strongest correlations to GPP, the NDVI, EVI and Clm, are all based on the difference between the red and the NIR reflectance. The PRI has no connection to the red absorption band, and the SIPI only makes slight use of the wavelengths in this region.

The poor overall performance of the PRI contrasts with Van Gaalen et al.'s [11] work, which indicated a good relationship between PRI and photosynthesis in Sphagnum samples. However, their experiments were over much shorter timescales (minutes rather than weeks or months); PRI may therefore be effective in providing information about shortterm changes in Sphagnum carbon flux, but not as useful in longer-term studies such as those involving satellite data. Harris [9] agrees with the current work in finding that PRI has a poor correlation with photosynthetic efficiency pooled amongst different Sphagnum species. Harris suggested that this might be due to species-specific differences, which is supported by our findings that PRI has a relatively strong linear relationship with GPP changes in S. capillifolium but not in S. papillosum. Interestingly, Van Gaalen et al. [11] and Harris [9] found most relationships between photosynthesis and PRI to be positive, whereas all significant relationships in this study were negative. This may be due to the time period over which measurements were taken; it is possible that the xanthophyll mechanism is also limited by prolonged drought. Another cause might be changes in the physical structure of the Sphagnum affecting light scattering and so disrupting the clarity of the wavelengths measured to calculate the PRI. Sims et al. [45] found that the PRI relationship with light use efficiency changed dramatically at their Californian heathland study site during a severe drought year in comparison with wetter years.

Harris [9] showed results from a laboratory study comparing photosynthetic efficiency (measured using chlorophyll fluorescence, $\Phi_{\text {PSII }}$ ) of water limited Sphagnum mosses to spectral indices. In agreement with the current work, Harris' study found that the NDVI gave a strong positive correlation with the photosynthesis of all samples (0.68 Pearson's correlation). However, Harris found that SIPI gave a better correlation with pooled photosynthetic efficiency data from all samples (-0.76). In our study, the SIPI gave significant results in both the field and the laboratory, but the agreement with GPP was not as strong as the NDVI, EVI or Clm.

Letendre et al. [13] also completed a field study comparing 
chamber carbon fluxes with spectral data from a handheld spectroradiometer but found that NDVI explained only $15 \%$ of the variation in GPP, whilst CIm explained 57\%. Our study showed similar results for CIm, with GPP explaining $60 \%$ of the variance in CIm in the field (and $43 \%$ in the lab), but we showed much stronger relationships for NDVI than Letendre et al., with GPP explaining $49 \%$ of the variance in NDVI in the field (and 38\% in the lab).

The field relationship between the NDVI, EVI and SIPI vegetation indices and GPP was found to vary by month, and to a lesser extent the CIm relationship. The slope of the relationship between these three indices and GPP in the lab work was closest to the steeper slope seen in March in the field data, compared to the shallower slopes later in the season. The steeper lines in the laboratory and in March are most likely due to healthy plants having high NDVI values, but not optimal conditions for photosynthesis. The most probable limiting factor in the laboratory was light availability, whilst in the colder months in the field both light and temperature would have affected photosynthesis.

In models which attempt to use vegetation indices to estimate peatland photosynthesis, the difference in slopes at different times of the year could be compensated for in a model that uses NDVI or EVI by adding a seasonal component, or a temperature component, as seen in Lees et al. [47]. This method would allow a linear relationship between GPP and the vegetation index to be assumed, but would reduce the unrealistically high values of GPP estimated in the colder months.

Comparing the field and laboratory results showed that pure Sphagnum in the laboratory had higher values than the field collars of the NDVI and EVI, and lower values of the SIPI and PRI. The differences between the Sphagnum/nonSphagnum dominated collars also suggested that Sphagnum has higher values of NDVI and EVI, and lower of SIPI and PRI. This agrees with Whiting's [48] findings that Sphagnum may give unusually high NDVI values compared to other blanket bog vegetation, due to its higher NIR reflectance. Similarly, Cole et al. [49] found that the PRI is very sensitive to the differences between bryophytes, shrubs and graminoids, particularly in the summer months. As Sphagnum is a more dominant component of GPP in the field earlier in the year, before leaf emergence in vascular plant, differences between the Sphagnum and non-Sphagnum dominated collars are smaller in the earlier months. The CIm did not show these differences, and might therefore be a good index for use over peatlands where vegetation composition is not known.

\section{CONCLUSIONS}

Both the water indices considered in this work had significant relationships with the moisture contents measured in the laboratory, but not with field data. The values of the water indices measured in the field were towards the lower end of those measured in the laboratory drought study on pure Sphagnum samples, suggesting that water indices can detect the higher water contents of Sphagnum mosses compared to other peatland vegetation species. Both water indices had similar relationships with water content in Sphagnum, suggesting that the broad-band NDWI can give equally strong results relative to the hyperspectral fWBI.

All vegetation indices tested in this study gave significant relationships with GPP in the laboratory and the field, although the PRI was clearly the least successful on mixed vegetation species. The indices which focused on the difference between the red and NIR zones (NDVI and EVI), and the CIm which uses the red-edge, gave the best agreement with GPP in both the field and the laboratory. Most of the vegetation indices considered showed consistent differences between Sphagnum and more mixed peatland vegetation, with the exception of the CIm. We therefore suggest that the CIm may be the best index to use in estimating GPP where the vegetation composition of a peatland area is unknown. The EVI gave slightly higher $\mathrm{R}^{2}$ results than the NDVI in both experiments, and can therefore be considered the best broadband index for estimating GPP. We suggest that the NDVI and EVI can give valuable large scale estimates from freelyavailable satellite data, particularly when modified with a seasonal factor. The PRI performed poorly on mixed vegetation species, but gave a strong result in detecting drought stress in S. capillifolium; we therefore recommend that the PRI may be best suited to small-scale estimation of GPP in known species.

Future work should consider calculating these indices from airborne and satellite data and assessing whether the relationships between water, GPP, and indices are consistent over different scales.

\section{APPENDIX}

To reduce the effect of varying background light levels, due to working in a laboratory with access to natural light, a PAR $\left(\mu \mathrm{mol} / \mathrm{m}^{2} / \mathrm{s}\right)$ sensor was added to the experimental set-up after noticing the effect in preliminary data. Calculations were then applied to remove the effect of background light levels on GPP, based on linear models fitted to control samples monitored across the measurement periods. In the first four weeks of the experiment, before the PAR sensor was added to the set-up, measurement time was used as a proxy for PAR and corrections applied accordingly. The correction equation is thus:

GPPcorrected $=$ GPP $-0.0204 \times \mathrm{PAR}+1.4$

And in the first four weeks:

GPPcorrected $=$ GPP $-0.0054 \times$ measurement time +0.2

\section{ACKNOWLEDGMENT}

Thanks are due to the Forsinard Flows RSPB reserve (particularly Daniela Klein) for site access and access to facilities, and also to Chobham Common NNR for allowing us to collect a few Sphagnum samples for methods testing. Thanks to Kevin White and Suvarna Punalekar for spectroradiometer training. Thanks to Alison Wilkinson for 
making 48 collars for the fieldwork, and to Mike Lees for making 40 collars for the laboratory study.

We are very grateful for the help of our field assistants Ainoa Pravia, Jose van Paassen, Paul Gaffney, Wouter Konings, Elias Costa, Zsofi Csillag, Valeria Mazzola, David and Parissa Lumsden, and Joe Croft.

Thanks also to the three anonymous reviewers for their useful comments on improving this manuscript.

\section{REFERENCES}

[1] T. Y. Minayeva, O. M. Bragg, and A. A. Sirin, "Towards ecosystem-based restoration of peatland biodiversity," Mires and Peat. vol. 19, 2017.

[2] E. Gorham, "Northern Peatlands: Role in the Carbon Cycle and Probable Responses to Climatic Warming," Ecol. Appl., vol. 1, no. 2, pp. 182-195, May 1991.

[3] J. Turunen, E. Tomppo, K. Tolonen, and A. Reinikainen, "Estimating carbon accumulation rates of undrained mires in Finland-application to boreal and subarctic regions," The Holocene, vol. 12, no. 1, pp. 69-80, Jan. 2002.

[4] JNCC, "Towards an assessment of the state of UK peatlands," 2011.

[5] A. Bonn, T. Allott, M. Evans, H. Joosten, and R. Stoneman, "Peatland restoration and ecosystem services: science, policy and practice.," Peatl. Restor. Ecosyst. Serv. Sci. policy Pract., 2016.

[6] W. Irving and L. Zhou, "Overview 2013 Revised Supplementary Methods and Good Practice Guidance Arising from the Kyoto Protocol"

[7] K. J. Lees, T. Quaife, R. R. E. Artz, M. Khomik, and J. M. Clark, "Potential for using remote sensing to estimate carbon fluxes across northern peatlands - A review," Sci. Total Environ., vol. 615, pp. 857-874, Feb. 2018.

[8] A. Harris, R. G. Bryant, and A. J. Baird, "Mapping the effects of water stress on Sphagnum: Preliminary observations using airborne remote sensing," Remote Sens. Environ., vol. 100, no. 3, pp. 363-378, Feb. 2006.

[9] A. Harris, "Spectral reflectance and photosynthetic properties of Sphagnum mosses exposed to progressive drought," Ecohydrology, vol. 1, no. 1, pp. 35-42, Feb. 2008.

[10] A. Harris, R. Bryant, and A. Baird, "Detecting nearsurface moisture stress in spp.," Remote Sens. Environ., vol. 97, no. 3, pp. 371-381, Aug. 2005.

[11] K. E. Van Gaalen, L. B. Flanagan, and D. R. Peddle, "Photosynthesis, chlorophyll fluorescence and spectral reflectance in Sphagnum moss at varying water contents," Oecologia, vol. 153, no. 1, pp. 19-28, Jul. 2007.

[12] K. M. Meingast et al., "Spectral detection of nearsurface moisture content and water-table position in northern peatland ecosystems," Remote Sens. Environ., vol. 152, pp. 536-546, Sep. 2014.

[13] J. Letendre, M. Poulin, and L. Rochefort, "Sensitivity of spectral indices to $\mathrm{CO}_{2}$ fluxes for several plant communities in a Sphagnum -dominated peatland,"
Can. J. Remote Sens., vol. 34, no. sup2, pp. S414S425, Nov. 2008.

[14] S. Bonnet, S. Ross, C. Linstead, and E. Maltby, "A review of techniques for monitoring the success of peatland restoration.," 2009.

[15] M. Strack and J. S. Price, "Moisture controls on carbon dioxide dynamics of peat- Sphagnum monoliths," Ecohydrology, vol. 2, no. 1, pp. 34-41, Mar. 2009.

[16] K. J. Lees, J. M. Clark, T. Quaife, M. Khomik, and R. R. E. Artz, "Changes in carbon flux and spectral reflectance of Sphagnum mosses as a result of simulated drought," Ecohydrology, Aug. 2019.

[17] P. McNEIL and J. M. Waddington, "Moisture controls on Sphagnum growth and CO 2 exchange on a cutover bog," J. Appl. Ecol., vol. 40, pp. 354-367, 2003.

[18] B. J. M. Robroek, M. G. C. Schouten, J. Limpens, F. Berendse, and H. Poorter, "Interactive effects of water table and precipitation on net $\mathrm{CO}_{2}$ assimilation of three co-occurring Sphagnum mosses differing in distribution above the water table," Glob. Chang. Biol., vol. 15, no. 3, pp. 680-691, Mar. 2009.

[19] E. Bortoluzzi, D. Epron, A. Siegenthaler, D. Gilbert, and A. Buttler, "Carbon balance of a European mountain bog at contrasting stages of regeneration," New Phytol., vol. 172, no. 4, pp. 708-718, Dec. 2006.

[20] L. Bragazza, "A climatic threshold triggers the die-off of peat mosses during an extreme heat wave," Glob. Chang. Biol., vol. 14, no. 11, pp. 2688-2695, Sep. 2008.

[21] R. A. Lindsay et al., "The Flow Country - The peatlands of Caithness and Sutherland," 1988.

[22] N. Littlewood, P. Anderson, R. Artz, O. Bragg, P. Lunt, and R. Marrs, "Peatland Biodiversity," 2010.

[23] M. H. Hancock, D. Klein, R. Andersen, and N. R. Cowie, "Vegetation response to restoration management of a blanket bog damaged by drainage and afforestation," Appl. Veg. Sci., vol. 21, no. 2, pp. 167-178, Apr. 2018.

[24] P. E. Levy and A. Gray, "Greenhouse gas balance of a semi-natural peatbog in northern Scotland," Environ. Res. Lett., vol. 10, no. 9, p. 094019, Sep. 2015.

[25] J. Laine and Helsingin yliopisto. Metsäekologian laitos., The intricate beauty of Sphagnum mosses : a Finnish guide for identification. Department of Forest Ecology, University of Helsinki, 2009.

[26] J. M. Clark, A. Heinemeyer, P. Martin, and S. H. Bottrell, "Processes controlling DOC in pore water during simulated drought cycles in six different UK peats," Biogeochemistry, vol. 109, no. 1-3, pp. 253270, Jul. 2012.

[27] J. M. Clark, P. J. Chapman, A. L. Heathwaite, and J. K. Adamson, "Suppression of dissolved organic carbon by sulfate induced acidification during simulated droughts.," Environ. Sci. Technol., vol. 40, no. 6, pp. 1776-83, Mar. 2006.

[28] J. W. Salisbury, "Spectral measurements field guide," 1998.

[29] G. Hambley, "The effect of forest-to-bog restoration on net ecosystem exchange in The Flow Country 
peatlands.," University of St Andrews, 2016.

[30] H. Rydin and J. K. Jeglum, The Biology of Peatlands. Oxford University Press, 2013.

[31] I. B. Strachan, E. Pattey, and J. B. Boisvert, "Impact of nitrogen and environmental conditions on corn as detected by hyperspectral reflectance," Remote Sens. Environ., vol. 80, no. 2, pp. 213-224, May 2002.

[32] K. Didan, A. Barreto Munoz, R. Solano, and A. Huete, "MODIS Vegetation Index User's Guide (MOD13 Series)," 2015.

[33] A. Huete, K. Didan, T. Miura, E. . Rodriguez, X. Gao, and L. . Ferreira, "Overview of the radiometric and biophysical performance of the MODIS vegetation indices," Remote Sens. Environ., vol. 83, no. 1-2, pp. 195-213, Nov. 2002.

[34] J. A. Gamon, J. Peñuelas, and C. B. Field, "A narrowwaveband spectral index that tracks diurnal changes in photosynthetic efficiency," Remote Sens. Environ., vol. 41, no. 1, pp. 35-44, Jul. 1992.

[35] J. Penuelas, I. Filella, and J. A. Gamon, “Assessment of photosynthetic radiation-use efficiency with spectral reflectance," New Phytol., vol. 131, no. 3, pp. 291-296, Nov. 1995.

[36] D. A. Sims and J. A. Gamon, "Relationships between leaf pigment content and spectral reflectance across a wide range of species, leaf structures and developmental stages," Remote Sens. Environ., vol. 81, no. 2-3, pp. 337-354, Aug. 2002.

[37] H. Wickham, "ggplot2: Elegant Graphics for Data Analysis.” Springer-Verlag New York, 2016.

[38] S. Vieira and R. Hoffmann, "Comparison of the Logistic and the Gompertz Growth Functions Considering Additive and Multiplicative Error Terms," Appl. Stat., vol. 26, no. 2, p. 143, 1977.

[39] A. Zeileis and T. Hothorn, "Diagnostic Checking in Regression Relationships.” R News, pp. 7-10, 2002.

[40] S. P. Millard, EnvStats : an R package for environmental statistics. 2013.

[41] A. Heinemeyer, J. Gornall, R. Baxter, B. Huntley, and P. Ineson, "Evaluating the carbon balance estimate from an automated ground-level flux chamber system in artificial grass mesocosms.," Ecol. Evol., vol. 3, no. 15, pp. 4998-5010, Dec. 2013.

[42] R Core Team, "R: A language and environment for statistical computing." Vienna, Austria, 2017.

[43] K. J. Lees, J. M. Clark, T. Quaife, R. R. E. Artz, M. Khomik, and J. Ritson, "Peatland vegetation: field and laboratory measurements of carbon dioxide fluxes and spectral reflectance." NERC Environmental Information Data Centre., 2019.

[44] J. Arroyo-Mora et al., "Airborne Hyperspectral Evaluation of Maximum Gross Photosynthesis, Gravimetric Water Content, and CO2 Uptake Efficiency of the Mer Bleue Ombrotrophic Peatland," Remote Sens., vol. 10, no. 4, p. 565, Apr. 2018.

[45] D. A. Sims, H. Luo, S. Hastings, W. C. Oechel, and A. F. Rahman, "Parallel adjustments in vegetation greenness and ecosystem $\mathrm{CO} 2$ exchange in response to drought in a Southern California chaparral ecosystem," Remote Sens. Environ., vol. 103, no. 3, pp. 289-303, Aug. 2006.

[47] K. J. Lees et al., "A model of gross primary productivity based on satellite data suggests formerly afforested peatlands undergoing restoration regain full photosynthesis capacity after five to ten years," $J$. Environ. Manage., vol. 246, pp. 594-604, Sep. 2019.

[48] G. J. Whiting, " $\mathrm{CO}_{2}$ exchange in the Hudson Bay lowlands: Community characteristics and multispectral reflectance properties," J. Geophys. Res., vol. 99, no. D1, p. 1519, Jan. 1994.

[49] B. Cole, J. McMorrow, and M. Evans, "Spectral monitoring of moorland plant phenology to identify a temporal window for hyperspectral remote sensing of peatland," ISPRS J. Photogramm. Remote Sens., vol. 90, pp. 49-58, Apr. 2014.

[50] J. W. . J. Rouse, R. H. Haas, J. A. Schell, and D. W. Deering, "Monitoring vegetation systems in the Great Plains with ERTS," Jan. 1974.

[51] British Geological Survey, "Geology of Britain." 2007.

[52] European environment agency, "Nationally designated areas (CDDA)." 2017. 